Kalpa Publications in Engineering
Volume 1, 2017, Pages 159-166
ICRISET2017. International Conference on Re-
search and Innovations in Science, Engineering
\&Technology. Selected Papers in Engineering

\title{
Simplified Approach for the Analysis of Three- Phase Self-Excited Induction Generator
}

\author{
Dr. N. G. Mishra ${ }^{1} \quad$ A. A. Shaikh ${ }^{2}$ \\ 1,2 Birla Viswakarma Mahavidyalaya, INDIA \\ ngmishra@bvmengineering.ac.in \\ aashaikh@bvmengineering.ac.in
}

\begin{abstract}
This paper presents a simplified approach to analyse the operational performance of a three phase Self-Excited Induction Generator (Cage type) under varying magnetizing component. SEIG are widely used in wind- mills due to many advantages, such as robustness, mechanical simplicity and low price but suffers from poor voltage regulation. However, the need of external capacitance to provide required reactive power is a major limitation particularly in standalone mode $[1,2]$ Therefore, it is necessary to study the effect of capacitance very precisely for practical importance. The proposed method is experimentally tested for a $3.7 \mathrm{~kW}$ induction generator.
\end{abstract}

\section{Introduction}

Induction machines operate in the generating and motoring modes fundamentally in the same manner except for the reversal power flow. Therefore, the equivalent circuit and the associated performance are valid for different slip. If the rotor is driven by a prime mover above the synchronous speed i.e. negative slip, the mechanical power of the prime mover is converted into electrical power to the utility grid/ load via stator winding. SEIG feed only through the stator and generally operate at low negative slip, approximately 1 to 2 per cent $[3,4]$. Therefore, power generated depends on rotor speed and the generator will always draw the reactive power from the grid if connected to the grid otherwise it is fed by externally connected capacitor bank. Capacitor bank feed the reactive power consumption partly or fully in order to achieve a power factor close to unity and make the induction machine to self-excite in case of standalone utility $[6,8]$.

The SEIG is a self-excited induction generator where a three-phase capacitor bank is connected across the stator terminals to supply the reactive power requirement of a load and generator was discovered by Basset and Potter in the 1930s. SEIG feed the energy through the stator only and generally operate at low negative slip [1] and the amount of power generated varies with slip. The reactive power consumption is partly or fully compensated by capacitors in order to achieve a power factor close to unity and make the induction machine to self-excite [2]. An induction generated 
connected with capacitor bank and excited in this manner is capable of acting as standalone generator supplying real and reactive power to a load $[9,10]$.

\section{Modelling of SCIG:}

The equivalent circuit of an induction generator (shown in Figure 1) is a very useful tool to analysis and computation of its performance under various conditions.

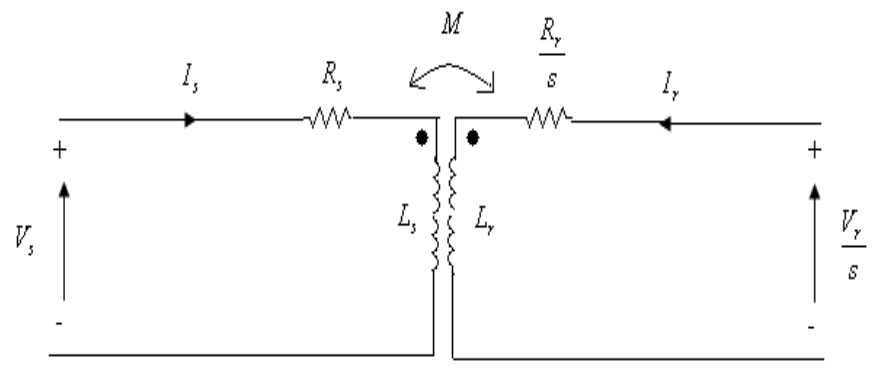

Figure 1 Equivalent circuit of Induction Generator

This section illustrates a simple per phase equivalent electric circuit of a three-phase induction machine. As the SEIG and DFIG use three-phase stator winding machine, the equivalent circuit is quite similar except that the rotor voltage in SCIG is very small as its rotor is short-circuited. The stator and rotor voltage equations from the equivalent circuit can be expressed based on Kirchhoff's laws.

$$
\begin{aligned}
& V_{s}=R_{s} I_{s}+j \omega_{s} L_{s} I_{s}+j \omega_{s} M I_{r} \\
& \frac{V_{r}}{s}=j \omega_{s} M I_{s}+\frac{R_{r}}{s} I_{r}+j \omega_{s} L_{r} I_{r}
\end{aligned}
$$

This may be expressed as;

$$
\begin{aligned}
& V_{s}=R_{s} I_{s}+j \omega_{s}\left(L_{s}-M\right) I_{s}+j \omega_{s} M\left(I_{s}+I_{r}\right) \\
& V_{s}=R_{s} I_{s}+j \omega_{s} l_{s} I_{s}+j \omega_{s} M\left(I_{s}+I_{r}\right)
\end{aligned}
$$

The stator voltage can be expressed as shown in equation.

$V_{s}=R_{s} I_{s}+j x_{s} I_{s}+j x_{m}\left(I_{s}+I_{r}\right)$

Similarly rotor voltage equation can be modified as;

$$
\begin{aligned}
& \frac{V_{r}}{s}=\frac{R_{r}}{s} I_{r}+j \omega_{s}\left(L_{r}-M\right) I_{r}+j \omega_{s} M\left(I_{s}+I_{r}\right) \\
& \frac{V_{r}}{s}=\frac{R_{r}}{s} I_{r}+j \omega_{s} l_{r} I_{r}+j \omega_{s}\left(I_{s}+I_{r}\right)
\end{aligned}
$$

Also the rotor voltage is given by equation.

$$
\frac{V_{r}}{s}=\frac{R_{r}}{s} I_{r}+j x_{r} I_{r}+j x_{m}\left(I_{s}+I_{r}\right)
$$

Power Flow:

The mechanical input power and stator power output are computed as given in equation 
$P_{m}=T_{m} \omega_{r}$ and $P_{s}=T_{e} \omega_{s}$

The torque and power balance is given by well-known equation

$T_{m}=J \frac{d \omega_{r}}{d t}+D \omega_{r}+T_{e}$

Assuming that the

total moment of inertia is $J\left(\mathrm{kgm}^{2}\right)$, and rotational and friction losses to be negligible, $J \frac{d \omega_{r}}{d t}=T_{m}-T_{e}$

Also for a loss-less generator at steady state $T_{m}=T_{e}$ and $P_{m}=P_{s}+P_{r}$

Therefore the rotor power are obtained are as follows,

$$
\begin{gathered}
P_{r}=P_{m}-P_{s}=T_{m} \omega_{r}-T_{e} \omega_{s} \\
=-T_{m}\left(\frac{\omega_{s}-\omega_{r}}{\omega_{s}}\right) \omega_{s}=-s T_{m} \omega_{s}=-s P_{s}
\end{gathered}
$$

Model of a SEIG of $0.23 \mathrm{kV}$, 4-pole, $2.9 \mathrm{kA}, 50 \mathrm{~Hz}$, developed in PSCAD is shown in Figure 2. In this case, the induction generator is connected with the grid and different faults are created using faults block from the PSCAD library [5]. As the induction generator is connected with the source, there is no need to connect the capacitor bank to feed necessary reactive power and is drawn from the source.

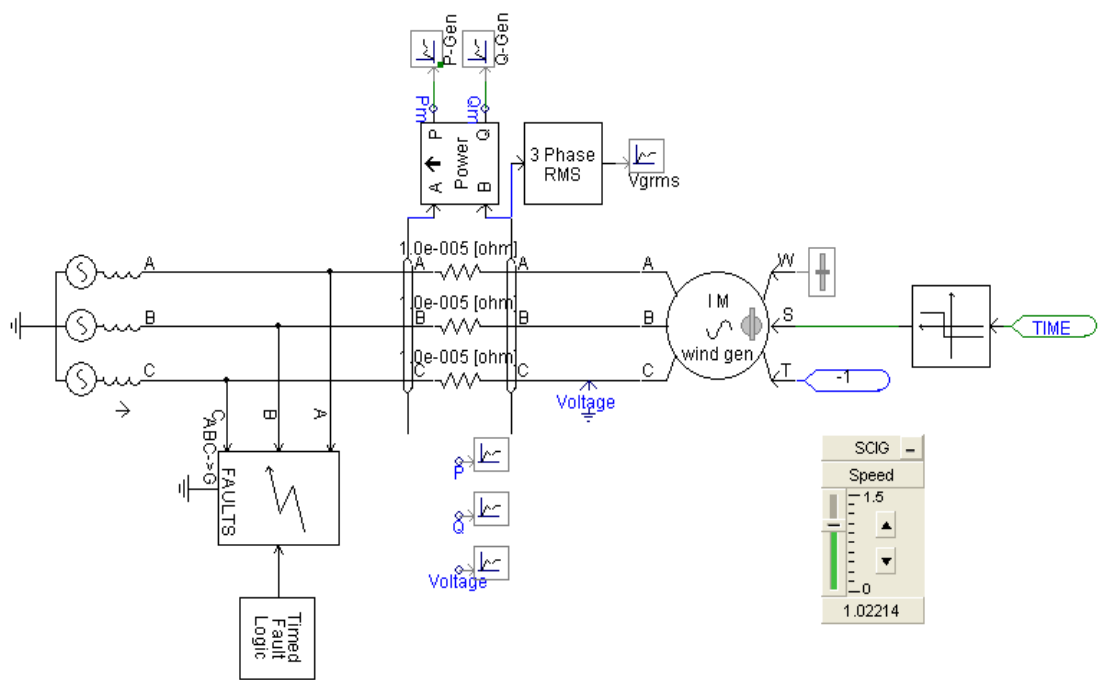

Figure 2 Basic schematic of SCIG

\section{Steady-State Operation}

The SEIG model, which has been developed using PSCAD using its various modules, is simulated for different control strategies under steady-state and transient conditions. In steady-state operation of a generator, the kinetic energy is converted into electrical energy and is delivered to the grid. The simulation is carried out at different speeds. It can be observed that rated active power is delivered to the grid while the reactive power is drawn from the grid when the wind turbine has been driven above 
at 1.02214 and 1.0514 times synchronous speed (Figures 3 and 4). The generator absorbs reactive power at all speeds, so compensation is required even during normal operation and especially when connected to a weak grid [8]. It can be seen that only one value of reactive power corresponds to a certain amount of generated active power. The particular value of the terminal voltage is shown in Figure 5. These results justify the basic concepts of the SEIG. The initial fluctuation in the values of powers and terminal voltage is due the starting condition.

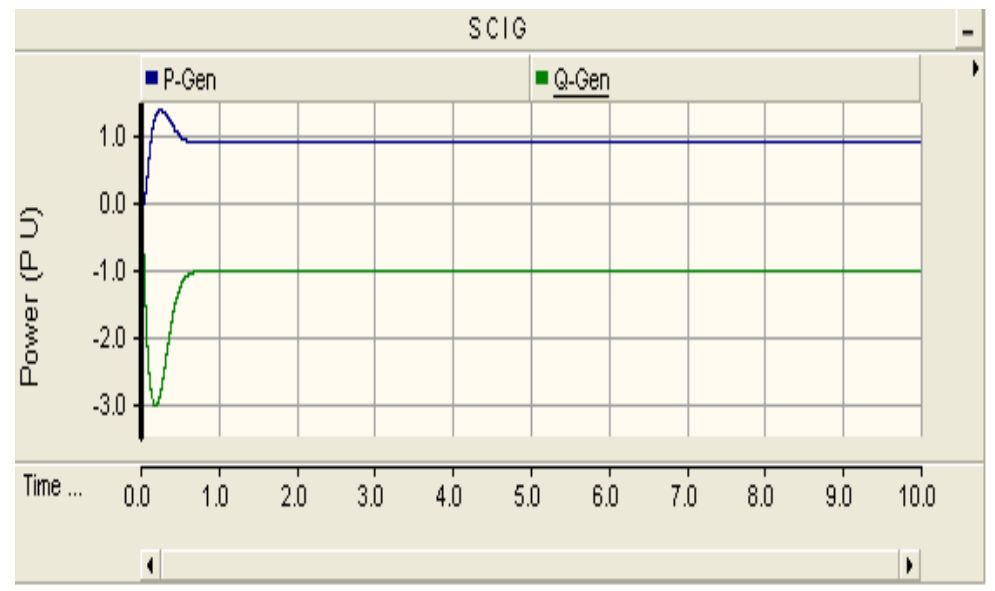

Figure 3 Steady-state operation at speed 1.0221 of $\mathrm{N}_{\mathrm{s}}$

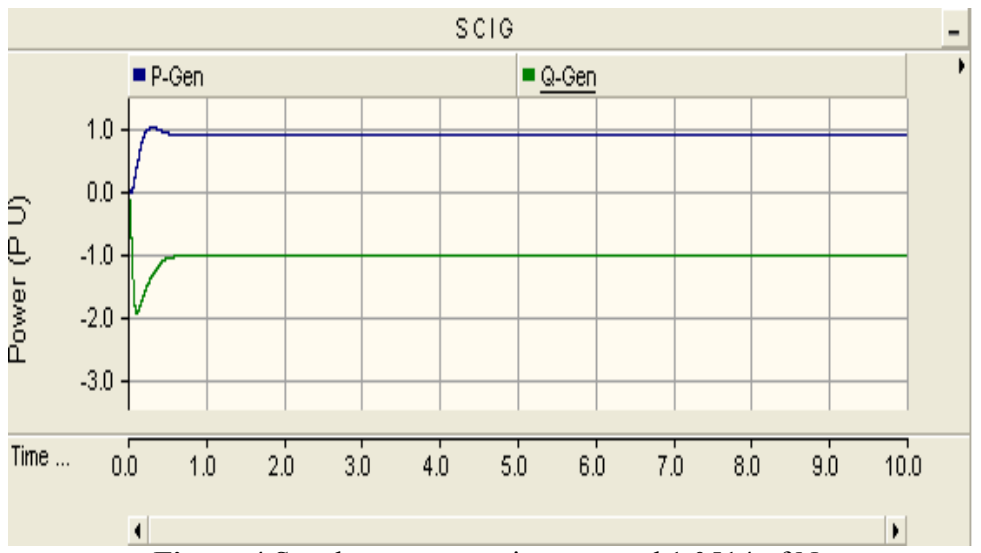

Figure 4 Steady-state operation at speed 1.0514 of $\mathrm{N}_{\mathrm{s}}$ 


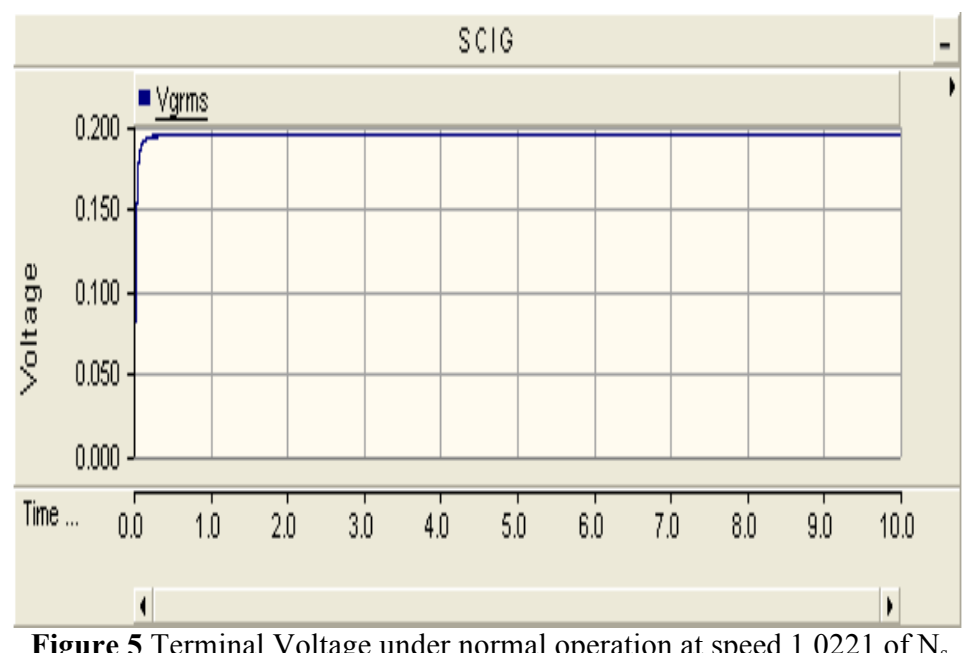

The reactive power consumption is determined by active power generation, terminal voltage and the generator parameters. It is also observed that the reactive power consumption is more in case of larger slip.

\section{Transient Operation}

To assess the behavior of SCIG under transient condition, a 3-phase fault at ' $t$ ' $=5 \mathrm{sec}$ with duration of $0.1 \mathrm{sec}$. was applied at the terminals of the wind generator. It can be observed from the results that whenever a fault occurs in the network, the generator terminal voltage reach a very low value (shown in Figure 6). At low voltage, a small amount of active power is fed to the grid as it is proportional to the terminal voltage and the effect can be observed in the Figure 7. At the same time, the potential energy of the shaft is transferred to the kinetic energy of the generator rotor. More acceleration results to more reactive power absorption during the fault period and can be seen in Figure 7. In this case rotor speed is limited using pitch control and reactive power consumption is restricted after the fault. This results in more acceleration and the generator speed increases due to unbalance between mechanical and electrical powers as shown in Figure 8.

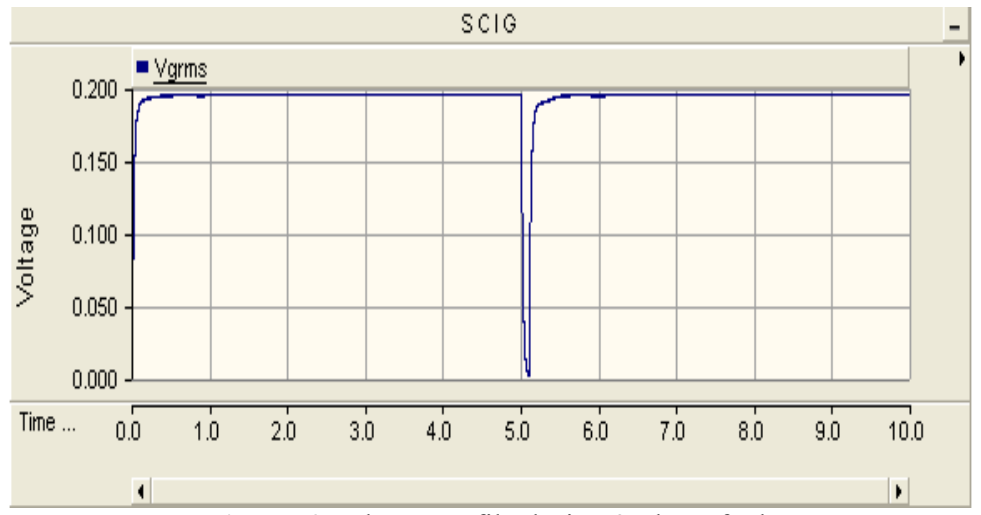

Figure 6 Voltage profile during 3-phase fault 


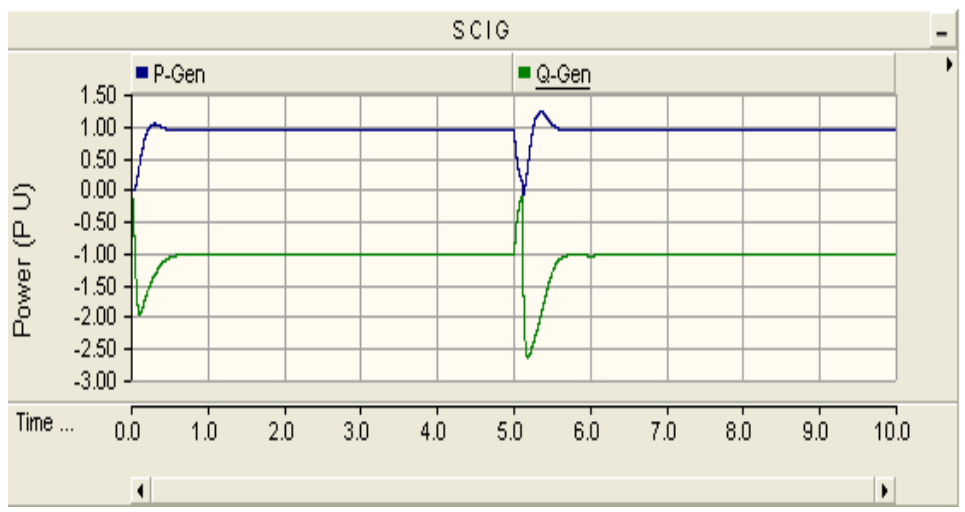

Figure 7 Active and reactive power during fault

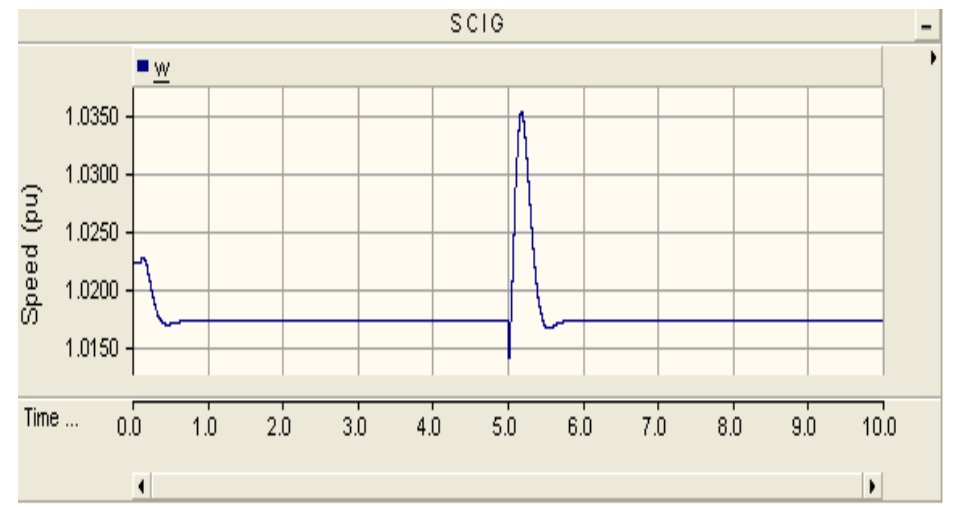

Figure 8 Speed curve during fault

The nature of transient fault, the clearance time and the short circuit power of the system determine whether a squirrel cage induction generator has reach its stability limit. There is more demand of reactive power once the stability limit is exceeded and over speeding causes a reactive power demand. Once the fault is cleared, the squirrel cage induction generator draws a large amount of reactive power from the grid because of its high rotational speed as seen in Figure 7.

\section{Experimental Work}

The simulation has been validated with the experimental set up to test SCIG under no load conditions. A general purpose 3-phase squirrel cage induction machine of $3.7 \mathrm{~kW}, 440 \mathrm{~V}$, 4-pole, $1500 \mathrm{rpm}$ is star connected and driven at different speeds. The induction machine under investigation was coupled to $220 \mathrm{~V}$ DC shunt motor that supplied the required mechanical power. Capacitor bank with different values is connected to meet the need of magnetising current. Terminal voltage and the frequency are observed in a capacitor self-excited induction generator for a given speed and capacitance. Figure 9 and 10 show the observations when a 3-phase capacitor bank of 10 micro-farad ( $2 \mathrm{kVAR}$ ) and 20 micro-farad (4 kVAR) is connected. 


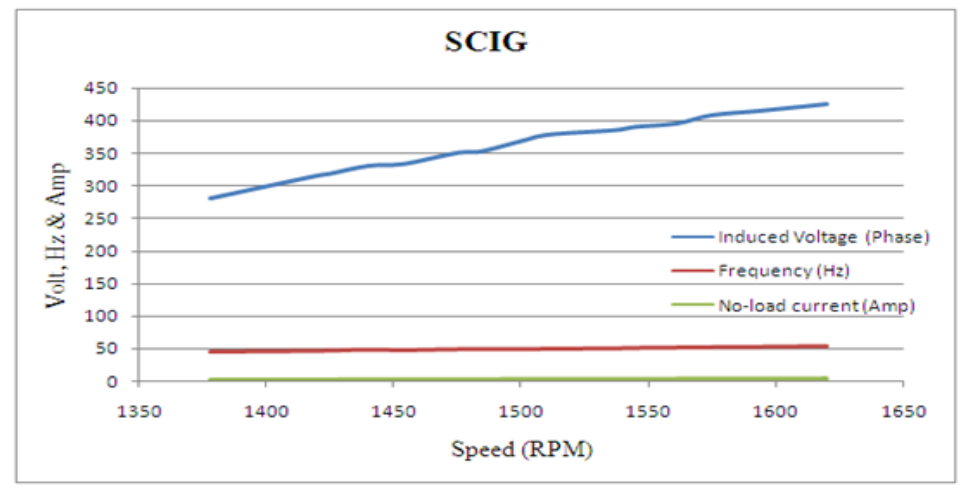

Figure 9 Speed v/s EMF, Frequency and No load current with capacitor of $10 \mu \mathrm{F}$

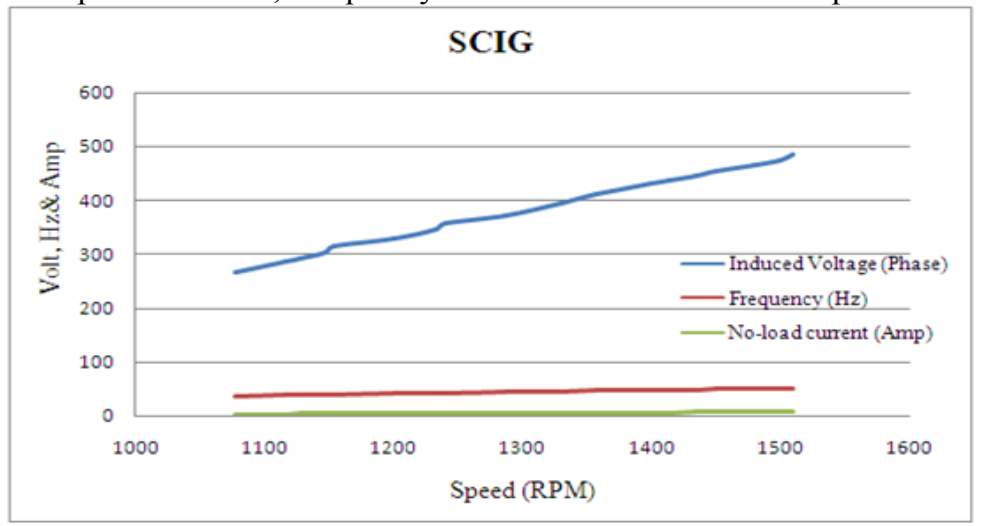

Figure 10 Speed v/s EMF, Frequency and No load current with capacitor of $20 \mu \mathrm{F}$.

The observations show that there is strong coupling between speed, magnetising current and induced voltages. The induced voltage, frequency and no-load current (magnetising current) increase with the increase in the speed. The test results show the effect of different capacitance and speed on the no load terminal voltage, frequency and no load current of the generator at no load. It is noted that the voltage generated is higher at higher values of operating speed and capacitor values. In order for self-excitation to occur, for a particular capacitance value there is a corresponding minimum speed, below which the output power of the generator is not available.

\section{Conclusion}

It is observed that for a self-excitation to generate sufficient electrical energy, a particular capacitance value is required to a corresponding minimum speed. It can be concluded from the simulations that there is a strong relation between active and reactive power, terminal voltage and rotor speed. The amount of over speeding during the fault is reduced by pitching the blades and thus controlling the mechanical. Reactive power generation is completely impossible and therefore additional controllable devices such as STATCOM, Capacitor bank etc. are required.

\section{References}

1. Ackermann T, "Wind Power in Power Systems", John Wiley and Sons Ltd., 2005. 
2. Murthy S. S., Singh B. P., Nagamani. C and Satyanarayana K.V.V.," Studies on the use of conventional induction motors as self-excited induction generator", IEEE Trans. On EC, Vol. 3, No.4, Dec 1988, p.p. 842-848.

3. Rai H C, Singh B., Murthy S.S., Singh B.P., Simplified Approach for the Analysis of Single-phase Self-excited Induction Generator. Vol 79, Feb, 1999.

4. I. Petra, S. Ion, M. Daniela, "Operation of an Induction Generator controlled by CSI circuit", International symposium on industrial electronics ISIE, p.p. 2661-2666, 2007.

5. Manitoba HVDC Research Centre. www.pscad.com.

6. Olimpo Anaya-Lara, Nick Jenkins, Eknayake J., Phill Cartwrite, Mike Hughes, "Wind Energy Generation, modeling and Control", John Wiley and Sons Ltd.2009,ISBN:978-0-47071433-1.

7. STTP on "Wind Power Electrical Systems", NITTR, Bhopal, $3^{\text {rd }}-14^{\text {th }}$ November, 2008.

8. R. C. Bansal, Three-phase Self-Excited Induction Generator, IEEE Trans on Energy Conversion, Vol.20 no. 2, June, 2005, pp. 292-299.

9. M. Ouali, M. Ben ali Kamoun, M. Chaabene," Investigation on the Excitation Capacitor for a Wind Pumping Plant Using Induction Generator," Smart Grid and Renewable Energy, 2011,2, pp 116-125.

10.S. Boora," On-Set Theory of Self-Excitation in Induction Generator," International Journal of Recent Trends In Engineering, Vol 2, No. 5, November 2009, pp 325-330. 